\title{
The impact of OFDI reverse technology spillovers on the China's export technological complexity
}

Meijia Fang, Yongjian Zong ${ }^{*}$

Nanjing University of Science and Technology, School of Economics and Management, China

* Corresponding author: Yongjian Zong, Professor, zongyongjian@sina.com

\begin{abstract}
This paper, by utilizing the inter-provincial panel data from 2009 to 2015 and the two-step system GMM, examines the impact of OFDI reverse technology spillovers on the export technological complexity in China. The result is that OFDI is a driving force for the export technological complexity. By further adding a series of control variables, the result showed that the impact of OFDI reverse technology spillovers on the export technological complexity has been increased. Therefore, the state should endeavor to encourage enterprises to "go global" and focus on the accumulated investment of domestic human and R\&D capital.
\end{abstract}

Key words: outward foreign direct investment; reverse technology spillover; export technological complexity; industrial structure; research and development

\section{Introduction}

With the Go Global strategy proposed in China, the outward foreign direct investment (OFDI) shows a significant increase. China's outward foreign direct investment flows increased from $2.89 \$$ billion in 2003 to $145.57 \$$ billion in 2015 . The flows ranked the 21st in 2003, while the flow in 2015 ranked 2nd across the global, which was a historic breakthrough. China is a trading power and the aggregate trade volume was continuously rising and the trade structure was also changing little by little, of which the proportion of export in high-tech products was gradually increased. Thus the export technological complexity has been steadily improved, which can be seen from the average number of all the provinces across the whole nation that the complexity increased from 28,907RMB in 2009 to 49,794RMB in 2015.

The Go Global strategy is to promote domestic technologies and improve the trade structure. So, what is the effectiveness of OFDI? Does OFDI have a positive impact on the export technological complexity? The paper is to discuss the above two issues.

Nowadays, the research on the OFDI and trade relations mostly focused on whether the OFDI and export are alternative or complementary. However, there are few researches on the relationship between OFDI and trade structure. Chen Juncong and Huang Fanhua (2013) pointed out that there is a dominant positive correlation between the current scale of OFDI 
and the export technological complexity of manufactured goods and OFDI greatly promoted the export technological complexity of manufactured goods ${ }^{1}$. Mo Sha and Li Ling (2015) compared the influence of FDI and OFDI on the trade structure. They assumed that apart from the influence of processing trade, the effect of OFDI on the export technology structure is much more significant by comparison with FDI and import trade ${ }^{2}$. And Yang lianxing and Liu Xiaoguang mainly analyzed the relationship between OFDI reverse spillover and export technological complexity from the industry aspect, and pointed out that the utility of OFDI reverse technology spillover is more significant in labor-intensive industries ${ }^{3}$.

To sum up, most of the current researches are mainly focused on the relationship between OFDI and export or the influential factors of OFDI reverse technology spillovers. There are few studies on the relationship between the reverse technology spillovers and export technological complexity, and no deep analysis from the region perspective, which is also a new idea for this paper.

\section{Research design and data processing}

\subsection{Empirical model}

In order to test whether OFDI reverse technology spillover will promote the export technological complexity, the method of Brach and Kappel (2009) ${ }^{4}$ is referred and the following econometric model is built:

$$
\ln E T C_{i t}=\alpha+\beta_{0} \ln S P_{i t}+\beta_{1} \ln I S_{i t}+\beta_{2} \ln B I_{i t}+\beta_{3} \ln H C_{i t}+\beta_{4} \ln R D_{i t}+\varepsilon_{i t}
$$

Wherein, $\mathrm{t}$ is time (year), i represents provinces, ETC is export technological complexity, SP is the technological spillover obtained by OFDI, IS is industrial structure, BI is the basic infrastructure, $\mathrm{HC}$ is the human capital, RD is R\&D investment, and $\varepsilon_{\mathrm{it}}$ is the random error.

\subsection{Variable selection and measure}

\subsubsection{Export Technological complexity (ETC)}

On the basis of Ricardo Hausmann, etc. (2007) ${ }^{5}$ and by the method of Chen Juncong and Huang Fanhua (2013), indicators are established and the ETC of all provinces is calculated. The specific method is as follows:

$$
P R O D Y_{j}=\sum \frac{\left(x_{j i} / X_{i}\right)}{\sum\left(x_{j i} / X_{i}\right)} Y_{i}
$$

Wherein, PRODY $\mathrm{j}_{\mathrm{j}}$ is the ETC of industry $\mathrm{j}, \mathrm{Y}_{\mathrm{i}}$ is the real per capita GDP, and $\mathrm{x}_{\mathrm{ji}} / \mathrm{X}_{\mathrm{i}}$ is the proportion of export volume of industry $\mathrm{j}$ in the total export volume.

And thus, the ETC of province $\mathrm{i}$ is as follows:

$$
E T C_{i}=\sum_{j \in z}\left(\frac{x_{j i}}{X_{z i}}\right) P R O D Y_{j}
$$

Wherein, ETC $_{\mathrm{i}}$ represents the ETC of province $\mathrm{i}$, and $\mathrm{j} \in \mathrm{z}$ represents that industry $\mathrm{j}$ belongs to industry $\mathrm{z}$. The weight is the share of industry $\mathrm{j}$ in industry $\mathrm{z}$ in province. 


\subsubsection{OFDI reverse technology spillover effect (SP)}

The foreign R\&D capital stock that overflows through the OFDI channel is used to measure the spillover effect. By the practice of Yi Changjun(2015), the foreign R\&D capital stock obtained from OFDI is first calculated across the whole nation, and then, the provincial foreign $R \& D$ capital is calculated in line with the proportion of the stocks in provinces accounted for those nationwide ${ }^{6}$. The formula is as follows:

$$
S P_{\mathrm{t}}=\sum \frac{O F D I_{\mathrm{nt}}}{G D P_{n t}} S R D_{n t}
$$

Wherein, $\mathrm{SP}_{\mathrm{t}}$ represents the stocks obtained during the period of $\mathrm{t}, \mathrm{OFDI}_{\mathrm{nt}}$ is the direct investment of China to the country $\mathrm{n}$ during this period, $\mathrm{GDP}_{\mathrm{nt}}$ is the Gross Domestic Product of country $n$ during this period, and $S R D_{n t}$ is the $R \& D$ capital stock of China to country $n$ during this period. As the statistics of the $R \& D$ capital stock of relevant countries can't be obtained directly, the perpetual inventory method is used, with the help of flow data, to calculate the stock, which is as follows: $\operatorname{SRD}_{\mathrm{nt}}=(1-\delta) \mathrm{SRD}_{\mathrm{nt}-1}+\mathrm{R}_{\mathrm{nt}}$, of which $\delta$ is $5 \%$, representing depreciation rate, $R_{n t}$ is the $R \& D$ expenditure of country $n$ of the year. 2009 is the base year, $\mathrm{SRD}_{2009}=\mathrm{R}_{2009} /(\mathrm{g}+\delta)$, $\mathrm{g}$ is the average annual growth rate of $\mathrm{R} \& \mathrm{D}$ expenditure. The proportion of R\&D expenditure of countries of GDP in the World Bank is used to calculate the expenditure flow and obtain the stock data. With 2009 as the base year, the GDP of every country is deflated by the GDP deflator.

On the basis of the whole country, the stock of every province is calculated. The formula is as follows:

$$
S P_{i t}=S P_{t} * \frac{O F D I_{i t}}{O F D I_{t}}
$$

Wherein, $\frac{\mathrm{OFDI}_{\mathrm{it}}}{\mathrm{OFDI}_{\mathrm{t}}}$ is the proportion of OFDI stock in the province $\mathrm{i}$ of the whole country, and $\mathrm{SP}_{\text {it }}$ is the foreign R \& D capital stock obtained by OFDI channel during the period of $\mathrm{t}$.

According to the foreign direct investment stock of China in the out-ward economic database, the 13 representative countries and regions are selected, including Hong Kong, the United States, Singapore, Australia, Netherlands, Britain, Russia, Canada, Indonesia, Luxembourg, Germany, France and Kazakhstan.

\subsubsection{Variable control}

The variable control including: Industrial structure (IS), proportion of the service sector of GDP is chosen to represent it. Basic Infrastructure (BI), the highways and railways mileage of all the provinces are selected to indicate the infrastructure level. Human Capital (HC), the employment proportion of people with college and above major in every province is used to represent it. R\&D investment (RD), in this paper, the number of staff (EP) and the investment in $\mathrm{R} \& \mathrm{D}(\mathrm{RDI})$ are used to measure innovation. 


\subsection{Data Sources}

The sample data of 31 provinces in mainland China from 2009 to 2015 are chosen for provincial panel data analysis. Wherein, the export statistics to calculate the ETC of all the provinces and the per capita GDP come from macroeconomic database in China. The OFDI data of China and all the provinces are from outward economic database in China. With 2009 as the base year, the GDP of every country is deflated by the GDP deflator. The statistics of R\&D proportion in GDP come from the World Bank, and the GDP of the above 13 countries and regions and its deflator is from the world macroeconomic database. The share of the service sector in GDP and the mileage data of the provincial highways and railways are from the China macroeconomic database. Employment proportion of people with college and above major in every province is from the China labor economy database. In addition, the staff in R\&D institutions and investment in R\&D investment are from the China science and technology database.

\section{Empirical analysis}

By using the GMM two-step estimation method, together with the above model to analyze the endogenous problems between OFDI reverse technology spillover and ETC with $\operatorname{lnSP}$ and $\operatorname{lnIS}$ as endogenous variables, and the rest as exogenous variables. The data all meet the basic test required by the GMM estimation method after adding the ETC lag items as a tool variable. The empirical results are completed by STATA14.0.

The empirical results of the model are shown in Table 1. It can be seen from models (1) to (5) is that the coefficients of the OFDI reverse spillover index (SP) are significantly positive and the estimated coefficients meet all the significant test of $1 \%$, which validate the relevant conclusions in the theoretical model-the OFDI reverse spillover is beneficial to the growth of ETC. And model (5) shows that with every 1\% change of OFDI reverse technology spillover, the ETC will be improved by 0.04. It can be gotten from the table is that OFDI will not only expand the overseas market to meet the global market but also innovate the relevant technologies and develop the emerging market, which is conducive to the optimization and upgrading of domestic IS and technical level. And OFDI reverse technology spillover output is less than 0.1 , indicating that its role in promoting is not enough, but there is much space for development.

In the control variables with the IS as an endogenous variable, the other coefficients are significantly positive except for the model (4). Model (5) shows the optimization of industrial structure is conducive to the upgrading of ETC to a great extent. Per $1 \%$ improvement in IS means $0.15 \%$ increase in ETC. Changes in industrial play a vital role in ETC.

The estimated coefficients of the basic infrastructure increase little in model (2) to (5), which further indicates the importance of the infrastructure. The improvement in infrastructure will have a significant impact on the upgrading of ETC. Especially in model (5), every 1\% increase in basic infrastructure will have $0.1 \%$ impact in ETC, which also shows the basic 
infrastructure reflects the development level of a region to a certain extent. A convenient infrastructure can ensure the effective production adjustment of the high-tech enterprises, thereby promoting the ETC of manufactured goods.

The estimated coefficients of HC are stable and the results of the table, with a positive effect on ETC, have passed significant statistics of $1 \%$, which also shows that a higher human capital indicates a stronger learning ability and a better absorption capacity to OFDI reverse technology spillover. HC is the core element of technology absorption.

The table shows that the increase of staff in R\&D investment will inhibit the improvement of ETC, which is against expectations. One possible reason may be that China's technologies are still lagging behind the developed countries and a relatively shortage in the $R \& D$ personnel. In the course of obtaining and transferring OFDI reverse technology into the applicable technologies in China, the staff in R\&D need to meet certain "threshold" and will play a significant role in ETC. However, at present, the staff fail to cross the "threshold", and thus, the result is against expectation. The $R \& D$ investment intensity meets the significant statistics of $5 \%$, meaning a positive role in ETC. The R\&D investment intensity, indicating the innovation capabilities in the region, becomes the main driving force for technologies through the internal information spillovers and is also the basis and support of technological innovation, with which enterprises achieve industrial development and technological breakthrough, thereby enhancing the level of ETC.

Table1-The impact of OFDI reverse technology spillover to ETC

\begin{tabular}{lccccc}
\hline & $(1)$ & $(2)$ & $(3)$ & $(4)$ & $(5)$ \\
\hline InSP & $0.01^{* * *}$ & $0.01^{* * *}$ & $0.009^{* * *}$ & $0.03^{* * *}$ & $0.04^{* * *}$ \\
& $(34.99)$ & $(23.39)$ & $(11.37)$ & $(8.38)$ & $(9.44)$ \\
InIS & $0.02^{* *}$ & $0.10^{* * *}$ & $0.09^{* * *}$ & 0.04 & $0.15^{* * *}$ \\
& $(2.28)$ & $(3.38)$ & $(2.99)$ & $(0.84)$ & $(3.42)$ \\
InBI & & $0.03^{* * *}$ & $0.05^{* * *}$ & $0.06^{* * *}$ & $0.10^{* * *}$ \\
& & $(6.73)$ & $(9.39)$ & $(4.99)$ & $(5.02)$ \\
InHC & & $0.03^{* * *}$ & $0.03^{* * *}$ & $0.02^{* * *}$ \\
& & $(6.29)$ & $(5.09)$ & $(2.78)$ \\
InEP & & & $-0.06^{* * *}$ & $-0.08^{* * *}$ \\
& & & & $(-5.56)$ & $(-6.36)$ \\
InRD & & & & $0.05^{* *}$ \\
& & & & & $(2.16)$ \\
Cons & $1.34^{* * *}$ & $1.56^{* * *}$ & $1.78^{* * *}$ & $1.25^{* * *}$ & $2.01^{* * *}$ \\
& $(23.43)$ & $(9.14)$ & $(10.42)$ & $(3.97)$ & $(4.00)$ \\
AR(1) & 0.01 & 0.01 & 0.01 & 0.009 & 0.01 \\
AR(2) & 0.79 & 0.67 & 0.84 & 0.72 & 0.96 \\
Hansen & 0.93 & 0.98 & 0.90 & 0.99 & 0.97 \\
\hline
\end{tabular}

NOTE: $* * *, * *, *$ represent the significant statistics at level of $1 \%, 5 \%, 10 \%$ respectively, the 
numbers in brackets mean $\mathrm{z}, \mathrm{AR}(1)$ and $\mathrm{AR}(2)$ are autocorrelation tests and Hansen is the excessive identification test.

\section{Conclusions and revelation}

In this paper, the inter-provincial panel data of 31 provinces in China from 2009 to 2015 are selected, and the impact of OFDI reverse technology spillover to ETC is discussed. Enterprises have access to foreign advanced technologies through OFDI, gain advanced research and development knowledge, so as to promote the technology complexity of domestic products. From the theoretical model to the empirical analysis in this paper, all shows that OFDI has a significant role in technologies. A further research indicates adding the measures of HD and R\&D investment will intensify the impact of OFDI reverse technology spillover to ETC, which also shows that the reverse spillover effect of international technology is inseparable from the technological absorption capacity of home country. IS and BI have a significant positive effect on ETC - the improvement of IS and BI will enhance ETC in China.

According to the above conclusions, the domestic enterprises can participate in the international labor division through OFDI, which is conducive to the improvement and upgrading of Chinese foreign trade structure. The government should encourage enterprises to invest directly in the countries with high-tech levels, which will help enterprises obtain the advanced knowledge and technologies. At the same time, the domestic infrastructure needs to be improved so that enterprises will have better access to production and export, industrial cluster will be formed and the optimization and upgrading of IS will be better facilitated. Moreover, the government should increase the R\&D capital investment and the accumulation of HC. The technology spillovers obtained by the OFDI need the corresponding domestic absorptive innovation capacity. The blind imitation cannot achieve technological breakthrough. Therefore, a further investment in HC is helpful to improve the absorption of OFDI reverse technology spillover effect, thus to promote ETC.

\section{References:}

1. Chen Juncong, Huang Fanhua, Out-ward foreign direct investment and export technological complexity, Word Economy Studies. 11(2013) 74-79+89.

2. Mo Sha, Li Ling, The impact of outward foreign direct investment on export technological complexity, Journal of Guizhou College of Finance and Economics. 02(2015) 63-73.

3. Yang Lianxing, Liu Xiaoguang, OFDI reverse technology spillover and the improvement of export technological complexity, Finance \& Trade Economics. 06 (2016) 97-112.

4. J Brach, RT Kappel, Global value chains, technology transfer and local firm upgrading in non-OECD countries, GIGA Working Paper. 110 (2009). 
5. $R$ Hausmann et al, What you export matters, Journal of Economic Growth.01 (2007)1-25.

6. Yi Changjun, Institutional environment, absorptive capacity and reverse technological spillovers of OFDI in emerging economies: a threshold test based on interprovincial panel data in China, Journal of Finance and Economics. 11(2015)4-19.

7. Lu Xiaodong, The changes of technological upgrading and export competitiveness in China: the combination of the Micro and the Macro, Word Economy.08 (2014)70-97.

8. Masanaga, Kumakura, What's so special about China's exports, a comment China and world economy. 05(2007)18-37.

9. Daudin et al, Who produces for whom in the world economy, Canadian Journal of Economics. 04(2011)1403-1437.

10. Chen Xiaohua, Liu Hui, The improvement of export technological complexity intensifies the employment discrimination - GMM estimates based on the global dynamic panel data, Studies in Science of Science.04 (2015)549-560.

11. Bin $X u$, The sophistication of exports: Is China special, China Economic Review.03(2010) 482-283.

12. Chen Xiaohua, Liu Hui, Will the continued export of products improve the export technological complexity - based on the heterogeneity of the geographical advantages of trade export, Journal of Finance and Economics. 01(2015)74-86.

13. Dai Zhongqiang, Does the protection of IPR improve the export technological complexity - empirical research from Chinese provincial level, Studies in Science of Science. 12(2014)1846-1858.

14. Zhao Hong, Peng Xin, The research on the measure and factors of export technological complexity in China, China Soft Science. 11(2014)183-192.

15. Zhou Lusong, Zheng Yali, The impact of the upgrading of export technological complexity on the income gap: Systemic GMM analysis based on provincial dynamic panel data, Journal of International Trade. 11(2014)61-71.

16. Du Yunsu, The empirical study of the impact of export technological complexity on Chinese economic growth, Journal of International Trade. 09(2014)3-12.

17. Liu Hui, Chen Xiaohua, Zhou Lusong, The impact of export technological complexity growth on energy efficiency - nonlinear test of threshold effect model based on transnational panel data, Journal of International Trade. 08(2014)25-35. 